Reprod. Nutr. Dévelop., 1981, 21 (2). 335-353.

\title{
Fixation de protéines chez les ruminants : évolution en fonction du poids des animaux ef variations selon la race, le sexe ou le niveau des apports alimentaires
}

\author{
par J. ROBELIN, M. THÉRIEZ *
}

Laboratoire de la Production de Viande
Laboratoire de la Production Ovine
I.N.R.A., Theix
Saint-Genes-Champanelle, 63110 Beaumont, France.

Summary. Protein retention in ruminants : changes with body weight and variation with breed, sex and feeding level.

Using a great amount of published and unpublished data, this paper analyzes changes in the protein content of the emply body of growing cattle and sheep (appendices 1,2 ). Protein content (p. 100 of empty body weight) usually increased from 6-7 p. 100 to 1820 p. 100 in cattle and to 14-18 p. 100 in sheep during fotal life. After birth, it decreased slowly, reaching $13-15$ p. 100 in 70 p. 100 mature-weight animals. Changes in water and lipid content were analyzed in relation to protein content (fig. 1).

Protein content (p. 100 of fresh weight) varied between 10 and 14 p. 100 in the adipose tissues, 15 and 16 p. 100 in the offals, 19 and 20 p. 100 in the muscles and skeleton and 28 and 30 p. 100 in the hide. Muscle protein amounted to 48 to 53 p. 100 of whole body protein.

Mean daily protein accretion increased in cattle from $100 \mathrm{~g}$ after birth to a maximum of $160-200 \mathrm{~g} /$ day at $200-300 \mathrm{~kg}$ of body weight and decreased afterwards (fig. 3). From $20 \mathrm{~g} / \mathrm{day}$ in very young lambs, it reached $30-40 \mathrm{~g} / \mathrm{day}$ at $20-30 \mathrm{~kg}$ of body weight. Daily protein accretion in $\mathrm{g}$ per $\mathrm{kg}$ of metabolic weight (W0.75) was similar in the two species $(5.5 \mathrm{~g}$ at birth, $2.8 \mathrm{~g}$ at $30 \mathrm{p} .100$ mature body weight and $1.2 \mathrm{~g}$ at $60 \mathrm{p} .100$ mature body weight). The lipid deposition was greater than protein accretion after 10 p. 100 mature body weight in sheep, but only after 20 p. 100 mature body weight in cattle. The ratio between lipid deposition and protein accretion was greater in sheep than in cattle.

Daily protein accretion, which varied according to sex and genotype, ranged between $150-235 \mathrm{~g} /$ day in cattle and between $32-54 \mathrm{~g} /$ day in sheep.

The protein content of sheep and cattle gain dropped when the feeding level increased. Simultaneously, the lipid content of gain increased and the animals were fafter at slaughter. However, it appears that the composition of sheep gain was less sensitive to feeding level than that of cattle.

\section{Introduction.}

L'amélioration de l'efficacité de transformation des aliments en protéines animales consommables par l'Homme est l'un des principaux objectifs des recherches 
sur la production de viande à partir des animaux domestiques. La connaissance de la quantité totale de protéines fixée dans les différents tissus, et de ses variations selon différents facteurs tels que l'âge, la race ou le sexe des animaux, ne présume en rien de la quantité de protéines réellement synthétisée. Elle permet, en revanche, de caractériser la capacité de production de protéines par les animaux, ef elle est à la base de la détermination des besoins alimentaires en protéines pour la croissance.

Cet article a pour objet de faire le point des connaissances sur les variations de la teneur en protéines des bovins et des ovins en croissance. On y analysera successivement :

1) L'évolution de la teneur en protéines du corps entier des bovins et des ovins en croissance, du fœtus à l'animal proche de l'état adulte, ef l'évolution simultanée des autres constituants chimiques.

2) Les variations de la teneur en protéines des principaux tissus, ainsi que la répartition des protéines corporelles entre ces différents tissus.

3) L'évolution avec l'âge des animaux, de la quantité de protéines fixée par jour, et de la quantité de lipides associée à cette accrétion.

4) Les variations de la quantifé de protéines fixée selon différents facteurs : race, sexe ou niveau des apports alimentaires.

\section{Evolution de la composition corporelle avec l'âge et le poids.}

L'analyse de cette évolution est basée sur la compilation de 1436 résultats publiés ou originaux, concernant la composition chimique globale du corps vide (corps entier - contenu digestif) d'agneaux ( $n=837$, dont 198 avant la naissance) ef de bovins ( $n=599$, dont 47 avant la naissance) en croissance. Ces résultats, présentés en annexes ( 1 et 2 ), recouvrent la quasi totalité de la croissance, des premiers stades fœitaux (poids $=200 \mathrm{~g}$ ) à 80 p. $100 \mathrm{du}$ poids adulte. On n'a retenu que les résultats de composition chimique mesurée directement après abattage ef broyage du corps entier des animaux. Les animaux, ainsi analysés, mâles entiers, castrés ou femelles, étaient de génotypes variés. Dans un premier temps, on a considéré l'évolution moyenne de la composition corporelle en fonction du poids vif vide, sans se préoccuper des variations de composition liées au sexe et au génotype qui font ensuite l'objet d'une analyse séparée. Cette évolution moyenne de la composition corporelle concerne des animaux ayant reçu une alimentation libérale et bien équilibrée.

L'évolution de la composition chimique corporelle a été analysée selon la relation allométrique classique entre le poids de chacun des principaux constituants chimiques, protéines, equ et lipides $(Y ; \mathrm{kg})$ et le poids vif vide $(X=$ poids vif - poids du contenu digestif $; \mathrm{kg}) ; \log Y=a+b \log X$. Dans cette relation, le coefficient d'allométrie (b) est un indicateur de la croissance relative de $Y$ par rapport à $X(b=(d y / y) /(d x / x))$. Par ailleurs, on a illustré cette analyse en rapportant sur graphique l'évolution en fonction du poids vif vide des teneurs en protéines, en eau et en lipides (en p. 100 du poids vif vide). Afin de rendre plus aisée la comparaison entre espèces, on a rapporté, sur les mêmes figures, les résultats obtenus sur les bovins et sur les ovins, en adoptant en abscisse une échelle décuplée $(X=10 \times$ poids vif vide) dans le cas des ovins. Dans la mesure où le poids adulte d'un bovin est approxi- 
mativement 10 fois plus élevé que celui d'un ovin, on peut ainsi comparer directement les résultats entre les deux espèces sur la base du stade de maturité.
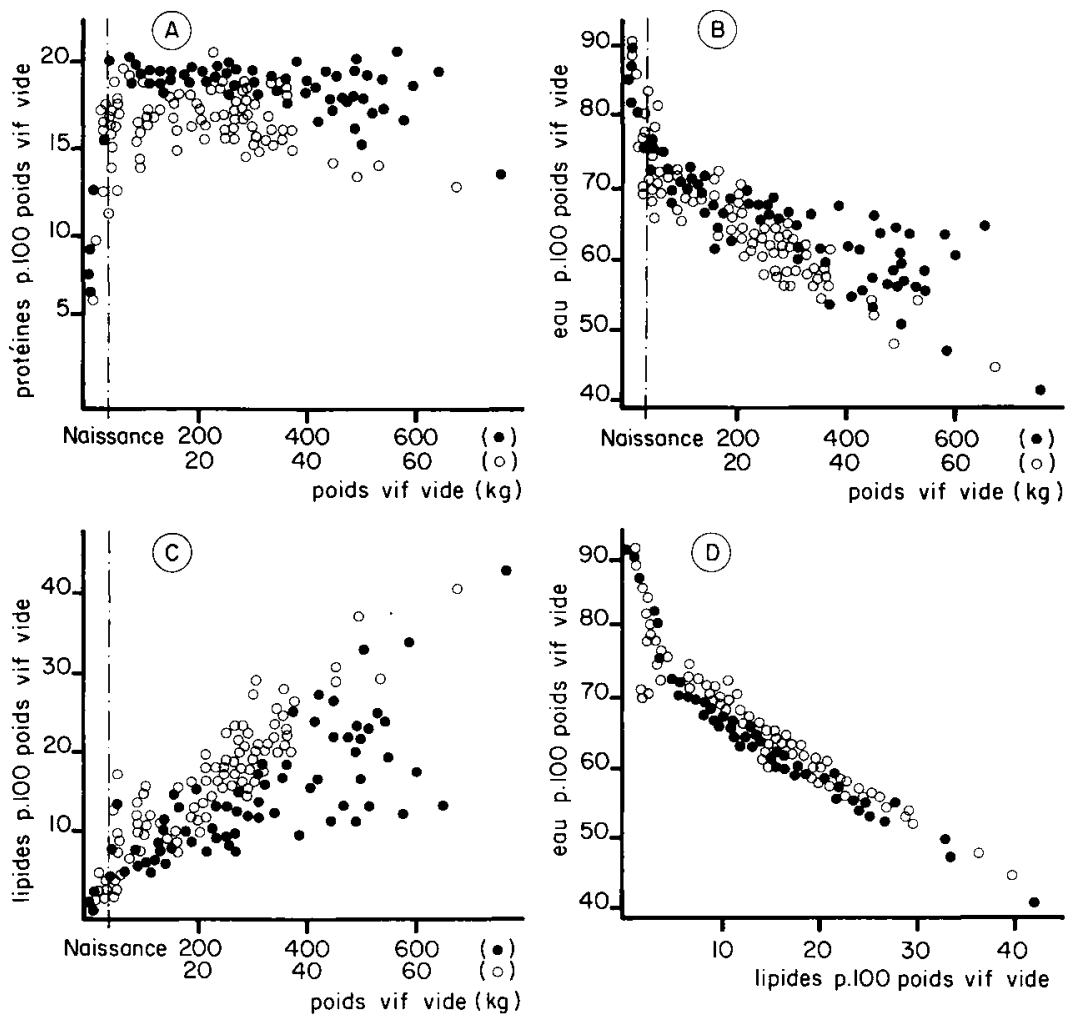

FIG. 1. - Evolution des protéines, de l'eau et des lipides corporels totaux (p. 100 poids vif vide) en fonction du poids vif vide chez les bovins ( $\bullet$ ) et les ovins ( $(0)$ en croissance, et relation entre l'eou et les lipides (Source : résultats rapportés en annexes 1 et 2 ).

Globalement, la composition chimique du corps vide des bovins et des ovins évolue de façon comparable (fig. 1). La teneur en protéines s'accroît de 6-7 p. 100 chez le fœitus de $200 \mathrm{~g}$ à 18-20 p. $100 \mathrm{chez}$ le veau nouveau-né et 14-18 p. $100 \mathrm{chez}$ l'agneau nouveau-né (fig. 1A). Ces valeurs, plus faibles en moyenne chez les agneaux, montrent que sur la base de ces critères, les ovins présentent, à la naissance, un état de maturité moins avancé que les bovins. Les différences importantes dans la teneur en protéines des agneaux nouveau-nés résultent beaucoup plus de différences entre auteurs (cf. annexe 1) que d'un effet propre du poids de naissance ou du génotype. Les résultats de Weniger, Funk et Konig (1955), Sykes et Field (1972) et de Houssin (résultats en cours de publication), obtenus sur des génotypes différents et avec des poids de naissance très variables, montrent que l'amplitude de variation est plus étroite, de 15,8 à 17,5 p. 100 seulement.

Après la naissance, la teneur en protéines du corps vide décroît lentement dans les deux espèces. Elle atteint 13-15 p. $100 \mathrm{chez}$ les ovins proches de l'état adulte. Chez 
les bovins, l'évolution est comparable, mais la teneur en protéines est en moyenne de 2 points (p. 100 poids vif vide) plus élevée que chez les ovins. Ces évolutions résultent du fait que la croissance relative des protéines, par rapport au poids vif vide, esł beaucoup plus élevée durant la vie fœtale $(b=1,21$ et 1,33 respectivement chez les bovins ef les ovins) qu'après la naissance ( $b=0,95$ et 0,97 respectivement) (tabl. 1$)$.

A l'opposé des protéines, l'eau et les lipides présentent une évolution pratiquement continue tout au long de la vie. La teneur en lipides s'accroît de 1 p. 100 à plus de 40 p. 100 (fig. 1C), tandis que la teneur en eau décroît de 91 p. 100 à 45-50 p. 100 (fig. 1B). En moyenne, les bovins ont une teneur en eau supérieure et une teneur en lipides inférieure à celles des ovins, l'écart étant voisin de 5 points (p. 100 du poids vif vide) pour chacun de ces deux constituants. La relation allométrique (tabl. 1) indique que l'évolution de l'eau est plus lente pendant la phase fotale $(b=0,95$ et 0,92 respec: tivement chez les bovins et les ovins) qu'après la naissance ( $b=0,88$ ef 0,85 respectivement). Enfin, la croissance relative des lipides reste pratiquement constante tout au long de la vie chez les ovins $(b=1,83$ ef 1,73 respectivement avant et après la naissance). Chez les bovins, elle est plus faible pendant la phase fotale $(b=1,48)$ qu'après la naissance $(b=1,70)$.

\section{TABLEAU 1}

Croissance relative des protéines, de l'eau ef des lipides corporels totaux

$(Y ; \mathrm{kg})$ en fonction du poids vif vide $(X ; \mathrm{kg})$ chez les ovins et les bovins :

$\left(Y=a X^{b}\right)$ valeurs moyennes estimées ò partir des résultats présentés en annexe (1 et 2$)$

\begin{tabular}{|c|c|c|c|c|c|c|c|c|c|}
\hline & \multirow[b]{2}{*}{$Y$} & \multicolumn{4}{|c|}{ Bovins } & \multicolumn{4}{|c|}{ Ovins } \\
\hline & & $a$ & $b$ & $\mathrm{Sb}\left({ }^{*}\right)$ & CVR $\left({ }^{*}\right)$ & $a$ & $\mathrm{~b}$ & $S b\left({ }^{*}\right)$ & CVR $\left(^{*}\right)$ \\
\hline $\begin{array}{c}\text { Avant la } \\
\text { naissance }\end{array}$ & $\begin{array}{l}\text { Protéines } \\
\text { Eau } \\
\text { Lipides }\end{array}$ & $\begin{array}{l}0,0765 \\
0,885 \\
0,00650\end{array}$ & $\begin{array}{l}1,21 \\
0,95 \\
1,48\end{array}$ & $\begin{array}{l}0,02 \\
0,01 \\
0,02\end{array}$ & $\begin{array}{r}10,2 \\
2,9 \\
8,5\end{array}$ & $\begin{array}{l}0,101 \\
0,814 \\
0,0117\end{array}$ & $\begin{array}{l}1,33 \\
0,92 \\
1,83\end{array}$ & $\begin{array}{l}0,04 \\
0,02 \\
0,16\end{array}$ & $\begin{array}{r}17,2 \\
6,9 \\
81,0\end{array}$ \\
\hline $\begin{array}{c}\text { Après la } \\
\text { naissance }\end{array}$ & $\begin{array}{l}\text { Protéines } \\
\text { Eau } \\
\text { Lipides }\end{array}$ & $\begin{array}{l}0,241 \\
1,227 \\
0,00255\end{array}$ & $\begin{array}{l}0,95 \\
0,88 \\
1,70\end{array}$ & $\begin{array}{l}0,01 \\
0,01 \\
0,05\end{array}$ & $\begin{array}{r}6,9 \\
7,9 \\
34,7\end{array}$ & $\begin{array}{l}0,179 \\
0,997 \\
0,0159\end{array}$ & $\begin{array}{l}0,97 \\
0,85 \\
1,73\end{array}$ & $\begin{array}{l}0,02 \\
0,01 \\
0,05\end{array}$ & $\begin{array}{r}10,0 \\
5,5 \\
27,6\end{array}$ \\
\hline
\end{tabular}

$\left({ }^{*}\right)$ Sb est l'écart type de b. CVR est le coefficient de variation résiduel de $Y$ en p. 100 de $Y$.

II existe des relations très étroites entre l'évolution de ces différents constituants chimiques. La majeure partie des variations de la composition corporelle au cours de la croissance, et des différences entre animaux de même poids vif vide, résulte des variations du poids des lipides corporels. Ainsi, la teneur en eau du corps vide est très étroitement corrélée $(R=0,97$ et 0,99 respectivement chez les ovins et les bovins) à la teneur en lipides. La relation entre ces deux critères n'est pas linéaire (fig. 1D). Elle pourrait être ajustée à une somme de deux exponentielles. Pour simplifier l'interprétation, nous l'avons ajustée à deux droites relatives, respectivement, à la phase fœtale et à la phase postnatale. Durant la phase fœtale, la teneur en eau décroît en moyenne de 4 points (p. 100 du poids vif vide) lorsque la teneur en lipides s'accroît de 1 point, dans les deux espèces bovine et ovine. Après la naissance, la teneur en eau ne décroît en moyenne que de 0,84 point lorsque la teneur en lipides 
s'accroît de 1 point (p. 100 poids vif vide). Par ailleurs, l'analyse de covariance révèle que pour une même teneur en lipides, les ovins renferment en moyenne plus d'eau ( +2 p. 100 poids vif vide) que les bovins. Les équations relatives à la phase postnatale sont les suivantes:

Bovins Eau (p. 100 PVV) $=74,7-0,824$ Lipides (p. 100 PVV) $R^{2}=0,989$ SE $=0,97$ Ovins Eau (p. 100 PVV) $=77,4-0,866$ Lipides (p. 100 PVV) $R^{2}=0,969 S E=1,50$

Enfin, le poids des protéines est bien sûr très étroitement relié au poids sec délipidé (poids vif vide - equ - lipides) dont il représente en moyenne 75 p. 100 ( $\pm 0,6$ p. 100) chez les fœius et 81 p. 100 ( $\pm 0,3$ p. 100) après la naissance, ces deux valeurs n'étant pas significativement différentes entre espèces bovine ef ovine. Ces relations statistiques entre l'eau, les lipides et les protéines, qui peuvent également être présentées sous la forme de la teneur en eau et en protéines dans la masse délipidée (poids vif vide - lipides), ont été mises en évidence depuis très longtemps dans différentes espèces (Moulton, 1923). Elles ont été confirmées plus récemment chez les oiseaux (Delpech, 1966), les lapins (Vigneron, Baron et Dauzier, 1971) et les bovins (Robelin et Geay, 1978). On peut, comme Widdowson (1968), attribuer ces relations à des coïncidences fortuites. Elles sont pourtant vraisemblablement le reflet d'un certain état d'équilibre entre les constituants chimiques au niveau tissulaire et cellulaire. Cet équilibre évolue au cours du développement en relation avec la croissance différentielle des tissus, ef avec l'accroissement relatif du nombre et de la taille des cellules de chaque tissu. Cependant, quelle qu'en soit la signification, ces relations statistiques étroites présentent un grand intérêt pour l'estimation de la composition corporelle chez les animaux, comme chez l'homme d'ailleurs.

En résumé, la teneur en protéines du corps vide évolue peu en valeur absolue après la naissance. Elle décroît lentement en relation avec l'accroissement de la teneur en lipides. Ses variations entre individus comme ses variations entre espèces bovine et ovine sont étroitement liées aux variations des teneurs en lipides et en eau.

\section{Evolution de la teneur en protéines des différents tissus.}

La composition chimique du corps vide et son évolution, au cours de la croissance, sont le reflet de la composition du croît des animaux au niveau global du corps entier. Il est intéressant de considérer également la distribution entre les différents tissus des constituants chimiques et notamment des protéines.

Les seuls résultats publiés permettant de comparer sur les mêmes animaux, la teneur en protéines des différents tissus et organes, restent à notre connaissance, ceux de Moulton, Trowbridge et Haigh (1922). Mais, en raison du nombre d'animaux relativement limité $(\mathbf{n}=31)$, du faible potentiel de rétention protéique de ces animaux en relation avec leur génotype (croisement Hereford), et surtout du fait que la composition chimique des muscles et des dépôts adipeux n'a pas été mesurée séparément, nous avons préféré faire cette étude sur la seule base de nos résultats personnels (Robelin, Geay et Beranger, non publié). Au cours de différentes études planifiées de l'évolution de la composition corporelle des bovins en croissance (Robelin, Geay, Beranger, 1974, 1977, 1979), on a mesuré par dissection complète, le poids de différents tissus et organes de 120 jeunes bovins mâles entiers, de génotypes Frison $(n=27)$. 
Salers $(n=20)$, Charolais $(n=27)$, Limousin $(n=30)$, Charolais $\times$ Frison $(n=12)$ ef Charolais $\times$ Salers $(n=4)$ dont le poids vif vide à l'abattage variait de 124 à $583 \mathrm{~kg}$. Après broyage de la totalité des tissus et organes, on en a déterminé séparément la composition chimique, teneurs en eau, lipides, protéines, cendres ef valeur calorifique. Les résultałs rapportés dans ce texte ne concernent que les protéines (fig. 2).
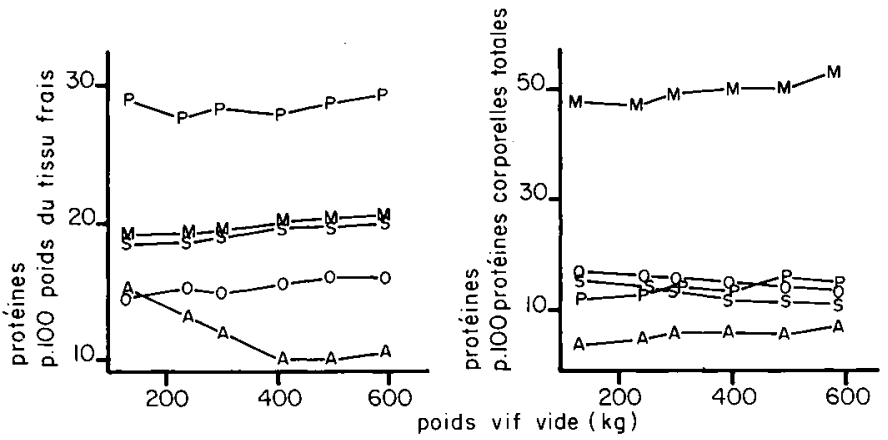

FIG. 2. - Evolution de lo teneur en protéines ( $p .100$ poids frais) de différents tissus : muscles (M), squelette $(S)$, dépôts adipeux $(A)$, peau $(P)$ et organes $(0)$ chez les bovins en croissance, et répartition des protéines corporelles dans chacun de ces tissus (Robelin, Geay ef Beranger, résultats non publiés, obtenus sur 120 animaux).

La teneur en protéines, exprimée en pourcentage du poids frais, varie selon les tissus de 10-14 p. 100 dans les dépôts adipeux, à 15-16 p. 100 dans les organes, 1920 p. 100 dans les muscles ef le squelette et 28-30 p. 100 dans la peau. Cette teneur évolue peu au cours de la croissance. Elle reste stable dans la peau ef les organes, aucune différence entre stades d'abattage n'étant significative $(P>0,01)$. Elle augmente significativement $(P<0,01)$ de 1 point (p. 100 du poids frais) dans les muscles et le squelette entre 15 et 65 p. 100 du poids adulte. Elle diminue significativement de 15,6 à 10,1 p. 100 dans les dépôts adipeux entre 15 et 45 p. 100 du poids adulte, puis reste siable ultérieurement. Cette diminution de la teneur en protéines va de pair avec un accroissement très rapide de la teneur en lipides, de 31,6 à 59,5 p. 100 et du volume moyen des adipocytes, de 4,7 à $69,5^{-4} \mu \mathrm{m}^{3}$ (Robelin, résultats en cours de publication).

Compte tenu des faibles variations de la composition chimique, et notamment de la teneur en protéines de la plupart des tissus, à l'exception des dépôts adipeux, c'est donc la croissance différentielle des tissus qui est pour une large part responsable des variations de la composition chimique globale du croît des animaux et par suite, de l'évolution de leur composition chimique corporelle.

La répartition des protéines dans l'ensemble du corps des bovins, dépend également en grande partie de la répartition pondérale des tissus ; 48 à 53 p. 100 des protéines corporelles sont localisés dans la musculature (fig. 2), 13 à 17 p. 100 sont localisés dans les organes, 13 à 16 p. 100 dans la peau, 12 à 17 p. 100 dans le squelette, et enfin 4 à 7 p. 100 seulement dans l'ensemble des dépôts adipeux. Cette répartition évolue peu au cours de la croissance. Elle correspond donc approximativement à la répartition des protéines fixées par jour dans les différents tissus. Pratiquement, ces 
résultats indiquent que chez les bovins, les protéines consommables par l'Homme, celles des muscles et des organes, ne représentent que 65 p. 100 de la quantité totale de protéines fixée par l'animal. Cette valeur correspond d'ailleurs à un maximum puisqu'une grande partie des organes n'entre pas habituellement dans l'alimentation humaine.

\section{Evolution de la quantité de protéines fixée en fonction de l'âge et du poids.}

La quantité de protéines apparemment fixée par jour, détermine en grande partie la croissance pondérale des animaux. En effet, chaque gramme de protéine apparemment fixé est accompagné de $3 \mathrm{~g}$ d'eau environ chez les bovins (Robelin et Geay, 1978).

On peut mesurer cette rétention chez les animaux en croissance par la méthode des bilans azotés ( $\mathrm{N}$ ingéré - $\mathrm{N}$ excrété) ou par celle des abattages comparatifs. On sait que la première méthode conduit généralement à une surestimation de l'azote réellement fixé car il est très difficile de mesurer, surtout chez les gros animaux, la totalité de l'azote excrété. La méthode des abattages est également critiquable puisqu'elle ne permet pas de mesurer individuellement la quantité de protéines apparemment fixée. En revanche, elle permet d'estimer avec précision, la quantité de protéines apparemment retenue en moyenne par un lot d'animaux, dans la mesure où les animaux abattus à chaque stade sont comparables.

On a estimé dans chaque espèce, la quantité de protéines fixée par jour et son évolution en fonction du poids et de l'âge des animaux, selon la méthode suivante : sur la base des résultats rapportées en annexe (poids, âge), on a déterminé une courbe de croissance selon une équation de Gompertz, qui, par dérivation, donne une estimation du gain de poids journalier. Ensuite, on a affecté à ce gain de poids, la composition du croît dérivée des équations d'allométrie présentées précédemment (tabl. 1).

L'évolution de la quantité de protéines fixée ainsi estimée, est rapportée sur la figure 3. Chez les bovins, elle est voisine de $100 \mathrm{~g} / \mathrm{jour}$ après les premiers stades postnataux. Elle atteint, en moyenne, 160 à $200 \mathrm{~g}$ chez les animaux de 200 à $300 \mathrm{~kg}$. Elle diminue ensuite et ne représente que $100 \mathrm{~g} / \mathrm{jour}$ environ chez les bovins de $500 \mathrm{~kg}$.

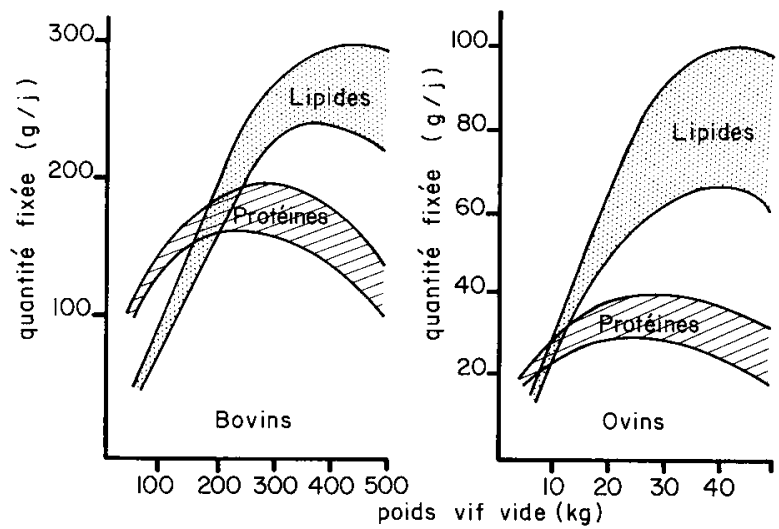

FIG. 3. - Evolution en fonction du poids des animaux des quantités de protéines ef de lipides fixées chez les bovins ef les ovins. 
La quantité de lipides fixée est plus faible que la quantité de protéines fixée jusqu'à $200 \mathrm{~kg}$. Cependant, elle s'accroît beaucoup plus longtemps que la quantité de protéines fixée, el atteint un maximum voisin de $300 \mathrm{~g} / \mathrm{jour}$ au poids de $450-500 \mathrm{~kg}$.

Chez les ovins, la quantité de protéines fixée est voisine de $20 \mathrm{~g} /$ jour après la naissance. Elle atteint $30-40 \mathrm{~g}$ au poids de $30-40 \mathrm{~kg}$ puis décroît lentement jusqu'à une valeur de $20-30 \mathrm{~g}$ au poids de $50 \mathrm{~kg}$. Dès le poids de $10-15 \mathrm{~kg}$, la quantité de lipides fixée est supérieure à la quantité de protéines fixée. Elle afteint 65 à $100 \mathrm{~g} / \mathrm{jour}$ au poids de $40 \mathrm{~kg}$.

On constate deux différences importantes entre les deux espèces bovine et ovine, l'une relative au taux d'accrétion des protéines (quantité de protéines fixée par jour rapportée au poids des protéines corporelles), l'autre relative au rapport entre les quantités de lipides et de protéines fixées. Le taux d'accrétion des protéines est plus élevé chez les ovins que chez les bovins comparés à même stade physiologique, mais l'écart entre espèces est d'autant plus faible qu'on se rapproche de l'état adulte.

A la naissance, le taux d'accrétion protéïque atteint 20-25 p. 1000 chez les ovins contre 10-12 p. 1000 seulement chez les bovins. Au tiers du poids adulte, il est égal à 5-7 p. 1000 chez les ovins contre 3-4 p. 1000 chez les bovins. Tout se passe comme si, à même pourcentage du poids adulte, les ovins étaient plus jeunes que les bovins. II est possible que cet écart entre les deux espèces ne relève pas d'une différence d'ordre biologique. En effet, lorsque l'on rapporte la quantité de protéines fixée au poids métabolique $\left(\mathrm{g} / \mathrm{kg}^{0,75}\right)$, on n'observe plus de différences entre espèces. A la naissance, la quantité de protéines fixée est voisine de $5,5 \mathrm{~g} / \mathrm{kg} \mathrm{P}^{0,75}$; elle n'atteint que $2,8 \mathrm{~g}$ au tiers du poids adulte, et $1,2 \mathrm{~g}$ seulement aux deux tiers du poids adulte dans les deux espèces.

La quantité de lipides fixée, associée à l'accrétion de protéines, est beaucoup plus élevée chez les ovins que chez les bovins. Ełant donné les valeurs calorifiques respectives des protéines et des lipides, le coût énergétique apparent de l'accrétion d'un gramme de protéines doit être plus élevé chez les ovins que chez les bovins. La quantité de protéines fixée par $\mathrm{kg}$ de poids métabolique étant comparable entre espèces (dans le cas d'une alimentation libérale), il en résulte qu'il faut au total ( $y$ compris les besoins d'entretien) plus d'énergie pour produire $1 \mathrm{~g}$ de protéines à partir des ovins qu'il n'en faut à partir des bovins comparés à même stade physiologique. Ainsi, une quantité d'énergie nette égale à une Unité Fourragère Viande distribuée à l'agneau de $25 \mathrm{~kg}$ permet de produire environ $35 \mathrm{~g}$ de protéines (Tissier et Thériez, 1978), alors que 5,3 UFV distribuées au taurillon de $250 \mathrm{~kg}$ permettent de produire environ $210 \mathrm{~g}$ de protéines (Geay et al., 1978). Ainsi, le coûł énergétique global de production d'1 kg de protéines est de 13 p. 100 plus élevé chez les ovins que chez les bovins, ces animaux étant comparés à même stade physiologique, environ 30 p. 100 du poids adulte, et dans des conditions d'alimentation libérale, afin de réduire l'incidence des besoins d'entretien.

\section{Variations de la quantité de protéines fixée selon le génotype, le sexe et le niveau des apports alimentaires.}

On observe des différences de composition corporelle chez les bovins selon leur génotype ef leur sexe, les conditions d'alimentation éfant comparables par ailleurs. 
Ces différences concernent surfout la teneur en lipides du corps vide qui peut varier chez des animaux de $500 \mathrm{~kg}$ (fig. 1C, annexe 2) de 12 p. 100 environ chez des mâles entiers de races à viande tardives (Charolaise, Limousine) à plus de 35 p. 100 des bœufs de races très précoces (Hereford, Angus).

La teneur en protéines varie en sens inverse dans des limites plus étroites. de 20 p. 100 chez les taureaux Charolais à 15 p. 100 environ chez les bœufs Herefords de même poids. Ces différences résultent pour une grande part de différences entre ces animaux dans leur potentiel d'accrétion des protéines. Ce potentiel qui atteint une valeur maximale vers $30-40$ p. 100 du poids adulte n'est bien sûr pas connu de façon précise ; on peut l'estimer à 230-260 g/jour chez les taureaux de races à viande tardives (Charolaise, Limousine) contre 180-220 g/jour chez les taureaux de race laitière précoce (Frisonne) (Robelin, Geay et Bonaiti, 1978). II ne dépasse guère $150 \mathrm{~g} / j o u r$ chez les bœufs de race très précoce (Hereford) (Jesse et al., 1976). La capacité d'ingestion de ces animaux n'étant pas très différente, voire légèrement supérieure chez les animaux dont le potentiel de croissance est plus faible, le supplément d'énergie ingéré par ces derniers est stocké sous forme de lipides.

La teneur en protéines du croît est plus faible chez les femelles que chez les mâles, de même génotype et de poids voisin $(250 \mathrm{~kg})$, respectivement 17,7 et 19,5 p. 100, d'après une estimation faite à partir de résultats publiés (Robelin et Daenicke, 1980). Ainsi, la quantité de protéines fixées par jour varie de $150 \mathrm{~g}$ chez des femelles Charolais $\times$ Salers à plus de $220 \mathrm{~g}$ chez des mâles de même génotype recevant une alimentation identique (Robelin, 1979).

On observe également de telles différences chez les ovins selon le génotype et le sexe des animaux. La quantité de protéines fixée varie de $35 \mathrm{~g} / j o u r$ chez des agneaux Charmois, à $41 \mathrm{~g}$ chez les Limousins, voire $54 \mathrm{~g}$ chez des croisés Berrichons alimentés de façon comparable (Thériez, résultats en cours de publication).

Selon McDonald, Greenhalgh et Grubb (1978), la teneur en protéines du gain de poids vif vide est plus élevée chez les mâles que chez les femelles (14,8 vs 12,8 p. 100) de même poids $(20 \mathrm{~kg})$. Par ailleurs, l'écart entre sexes s'accroît avec le poids des animaux. Ainsi, à $35 \mathrm{~kg}$, les valeurs correspondantes sont respectivement égales à 14,0 et 11,5 p. 100 . Les résultats de Thériez (résultats en cours de publication) sont comparables. La quantité de protéines fixée par jour est également plus élevée chez les mâles que chez les femelles croisés lle de France (38 vs $32 \mathrm{~g})$ alors que leur croît global est comparable (239 vs $235 \mathrm{~g} / \mathrm{jour}$ ).

Rappelons que ces différences de potentiel d'accrétion de protéines et de composition du croît se traduisent à l'abattage, essentiellement par des variations de teneur en lipides de la masse corporelle. En effet, chez les ovins comme chez les bovins (Jarrige et al., 1978 ; Robelin et Geay, 1978), la teneur en protéines de la masse délipidée (poids vif vide - lipides) est très peu variable quels que soient la race ou le sexe des animaux.

La quantité de protéines fixée, comme la croissance pondérale globale d'ailleurs, dépend évidemment de la quantité d'aliment ingérée par les animaux. On constate, en outre, que la composition du croît, ef en particulier le rapport entre les quantités de lipides et de protéines fixées, varie selon les apports alimentaires d'énergie et de protéines. Un nombre important d'essais d'engraissement comportant différents 
niveaux d'apports alimentaires ont été effectués chez les bovins entre 20 et 55 p. 100 du poids adulte (cf. revue de Robelin et Daenicke, 1980).

Les résultats de ces travaux concordent assez bien : les animaux ayant reçu une alimentation libérale présentent, lorsqu'ils sont abattus au même poids, un état d'engraissement - quantité de dépôts adipeux ou de lipides dans la carcasse - plus élevé que les animaux ayant subi une restriction alimentaire globale (énergie et azote) ; ils renferment par conséquent moins de protéines. Les quantités de protéines et de lipides fixées sont accrues respectivement de 8 et 18 p. 100 lorsque la croissance pondérale est accrue de 10 p. 100 sous l'effet d'une élévation du niveau des apports alimentaires (Robelin, 1979). Cet effet est toutefois variable selon le génotype des animaux. II est beaucoup plus prononcé chez les animaux à développement précoce, tels que les taurillons Frisons, que chez les animaux plus tardifs, à potentiel de croissance plus élevé, tels que les Charolais (Geay, Robelin, Béranger, 1976).

Cet effet du niveau des apports alimentaires n'a pas été mis en évidence de manière aussi nette chez les ovins. Certains résultats (Pallson et Verges, 1952 ; Norton, Jagusch et Walker, 1970 ; Searle, McGraham et O'Callagan, 1972) sont comparables à ceux obtenus chez les bovins, d'autres sont opposés (Andrews et Ørskov, 1970 ; Morgan et Owen, 1972), d'autres enfin ne permettent pas de conclure à un effet significatif (Gardner, Hogue et Bensadoun, 1964 ; Andrews, Kay et $\varnothing$ rskov, 1969 ; Arnold et al., 1969 ; Burton ef Reid, 1969 ; McManus ef al., 1974 ; Murray et Slezacek, 1976 ; Kellaway, 1973 ; O’Donovan, 1974 ; Thériez, résultats en cours de publication).

Il n'y a pas, a priori, de raison fondamentale pour que cet effet soit différent entre ces deux espèces. Il semble seulement que la composition du croît des ovins soit moins sensible que celle des bovins aux variations du niveau des apports alimentaires. En effet, une réduction des apports alimentaires qui se traduit par une diminution de 50 p. 100 de la vitesse de croissance n'entraîne pas chez les ovins de modification sensible de la composition des animaux à l'abattage. Il faut atteindre une réduction de 60 à 70 p. 100 de la vitesse de croissance pour que la teneur en lipides du croît soit affectée significativement.

\section{Conclusions.}

On peut retenir de cette éfude essentiellement trois points :

1) La teneur en protéines des animaux est assez peu variable en valeur ubsolue (14 à 20 p. 100 environ). Cette variation n'est cependant pas négligeabile en valeur relative. Par ailleurs, elle résulte des variations dans la composition du croît dont l'amplitude est bien sûr plus grande. La teneur en protéines du croît varie avec l'âge des animaux de 20 à 12 p. 100 environ. Elle varie également selon le niveau des apports alimentaires, le génotype et le sexe des animaux.

2) La moitié des protéines fixée par jour est localisée dans la musculature, et au total 60 à 70 p. 100 des protéines fixées entrent normalement dans l'alimentation humaine.

3) La quantité de lipides fixée, associée à la rétention de protéines, s'accroît avec l'âge des animaux. Le coût énergétique de production des protéines est donc d'autant plus élevé que les animaux sont abattus plus âgés. 
La connaissance de ces variations dans les quantités de protéines fixées, jointe à l'amélioration de la connaissance de l'utilisation digestive de l'azote (Jarrige, Journet et Vérité, 1978), ont permis de faire récemment des progrès importants dans la détermination des besoins alimentaires globaux en azote des ruminants.

La rétention apparente de protéines, dont on vient d'analyser quelques facteurs de variations, ne représente que 20 à 30 p. 100 de la quantité de protéines synthétisée chez les très jeunes animaux, rats ou agneaux (Millward et al., 1975 ; Arnal, 1977). De plus, cette proportion décroît avec l'âge des animaux. La différence entre synthèse et rétention apparente, c'est-à-dire le renouvellement des protéines, ef plus particulièrement le coût énergétique de ce renouvellement, représente une part importante du besoin énergétique non productif (entretien) des animaux en croissance. Les variations de ce besoin en fonction du niveau des apports alimentaires, de la vitesse de croissance globale ou de la quantité de protéines fixée, sont encore très mal connues. En ce sens, toute amélioration des connaissances dans ce domaine sur les animaux domestiques, et particulièrement sur les bovins, constituerait un progrès dans la connaissance du métabolisme énergétique de ces animaux.

6e Réunion du groupe Développement I.N.R.A., Clermont-Ferrand/Theix, 22-23 mai 1980. 
ANNEXE 1

Résultats sur la composition chimique globale des ovins en croissance

\begin{tabular}{|c|c|c|c|c|c|c|c|c|}
\hline \multirow{2}{*}{$\begin{array}{l}\text { Auteurs } \\
\text { (1) }\end{array}$} & \multirow{2}{*}{$\begin{array}{l}\text { Race } \\
\left({ }^{(}\right)\end{array}$} & \multirow{2}{*}{$\begin{array}{c}\text { Sexe } \\
\left({ }^{3}\right)\end{array}$} & \multirow{2}{*}{ Nombre } & \multirow{2}{*}{ Age (j) } & \multirow{2}{*}{$\begin{array}{l}\text { Poids vif } \\
\text { vide }(\mathrm{kg})\end{array}$} & \multicolumn{3}{|c|}{ p. 100 poids vif vide } \\
\hline & & & & & & Eau & Lipides & Protéines \\
\hline 1 & 1 & 2 & 6 & 270 & 23,4 & 63,06 & 15,44 & 18,24 \\
\hline$i$ & 1 & 3 & 6 & 270 & 22,5 & 61,59 & 14,13 & 20,47 \\
\hline 1 & 2 & 2 & 6 & 270 & 28,3 & 60,58 & 17,42 & 18,09 \\
\hline 1 & 2 & 3 & 6 & 270 & 28,4 & 61,06 & 16,67 & 18,59 \\
\hline 2 & 3 & 1 & 6 & 130 & 36,2 & 58,20 & 20,20 & 18,40 \\
\hline 2 & 3 & 1 & 6 & 130 & 36,1 & 57,00 & 21,60 & 18,10 \\
\hline 2 & 3 & 1 & 6 & 130 & 36,3 & 57,10 & 21,70 & 17,80 \\
\hline 2 & 3 & 1 & 6 & 130 & 35,0 & 58,30 & 19,70 & 18,60 \\
\hline 2 & 3 & 1 & 6 & 130 & 34,2 & 56,80 & 21,20 & 18,60 \\
\hline 3 & 4 & 3 & 4 & 157 & 13,5 & 67,70 & 10,52 & 16,89 \\
\hline 3 & 4 & 3 & 4 & 205 & 18,9 & 63,48 & 15,67 & 16,25 \\
\hline 3 & 4 & 3 & 8 & 255 & 24,8 & 58,19 & 22,17 & 15,69 \\
\hline 3 & 4 & 3 & 4 & 339 & 34,0 & 56,23 & 25,09 & 14,89 \\
\hline 3 & 4 & 3 & 6 & 452 & 49,3 & 47,69 & 36,53 & 12,86 \\
\hline 4 & 5 & 1 & 5 & 7 & 4,9 & 73,87 & 6,32 & 16,32 \\
\hline 4 & 5 & 1 & 5 & 35 & 11,5 & 68,19 & 11,57 & 16,71 \\
\hline 4 & 5 & 1 & 5 & 70 & 19,5 & 66,29 & 12,48 & 17,49 \\
\hline 4 & 5 & 1 & 5 & 112 & 28,8 & 64,54 & 14,18 & 17,34 \\
\hline 5 & 1 & 3 & 4 & 54 & 10,7 & 69,20 & 9,50 & 16,70 \\
\hline 5 & 1 & 2 & 4 & 54 & 10,7 & 68,00 & 10,20 & 17,00 \\
\hline 5 & 1 & 3 & 4 & 100 & 16,0 & 72,20 & 6,40 & 14,50 \\
\hline 5 & 1 & 2 & 4 & 100 & 16,0 & 71,70 & 7,60 & 15,60 \\
\hline 5 & 1 & 3 & 4 & 142 & 21,4 & 69,40 & 11,00 & 15,50 \\
\hline 5 & 1 & 2 & 4 & 142 & 21,4 & 66,40 & 13,50 & 16,10 \\
\hline 5 & 1 & 3 & 4 & 198 & 26,7 & 64,10 & 15,80 & 15,80 \\
\hline 5 & 1 & 2 & 4 & 198 & 26,7 & 62,00 & 18,10 & 15,70 \\
\hline 5 & 1 & 3 & 4 & 262 & 32,0 & 62,20 & 17,20 & 15,30 \\
\hline 5 & 1 & 2 & 4 & 262 & 32,0 & 61,20 & 19,40 & 15,50 \\
\hline 5 & 1 & 3 & 4 & 363 & 37,4 & 60,60 & 19,80 & 15,70 \\
\hline 5 & 1 & 2 & 4 & 363 & 37,4 & 55,40 & 25,60 & 14,70 \\
\hline 5 & 6 & 3 & 4 & 30 & 10,2 & 65,30 & 14,20 & 16,20 \\
\hline 5 & 6 & 2 & 4 & 30 & 10,2 & 64,60 & 14,70 & 16,20 \\
\hline 5 & 6 & 3 & 4 & 68 & 15,3 & 70,90 & 8,30 & 16,70 \\
\hline 5 & 6 & 2 & 4 & 68 & 15,3 & 69,40 & 9,10 & 17,60 \\
\hline 5 & 6 & 3 & 4 & 124 & 20,4 & 70,20 & 9,10 & 17,00 \\
\hline 5 & 6 & 2 & 4 & 124 & 20,4 & 68,20 & 11,10 & 16,80 \\
\hline 5 & 6 & 3 & 4 & 164 & 25,5 & 64,30 & 16,60 & 15,70 \\
\hline 5 & 6 & 2 & 4 & 164 & 25,5 & 62,80 & 17,70 & 15,50 \\
\hline 5 & 6 & 3 & 4 & 192 & 30,6 & 61,00 & 19,80 & 15,40 \\
\hline 5 & 6 & 2 & 4 & 192 & 30,6 & 60,70 & 20,70 & 15,40 \\
\hline
\end{tabular}

(1) Auteurs. - 1 : Gharaybeh ef al. (1969) ; 2 : Andrews, Kay ef $\varnothing$ rskov (1969) ; $3:$ Burton et Reid (1969) ; 4 : Robelin ef al. (1977) ; 5 : Kellaway (1973) ; 6 : Gardner, Hogue et Bensadoun (1964) ; 7 : Thériez (résultats en cours de publication) ; 8 : Houssin (résultats en cours de publication) ; 9 :Weninger, Funk et Konig (1955) ; 10 : Sykes et Field (1972) ; 11 : Langlands ef Sutherland (1968) ; 12 : Rattray et al. $(1974 a, b) ; 13$ : Jagusch, Norton et Walker (1970) ; 14 : Drew et Reid (1975) ; 15 : Chiou et Jordan (1973) ; 16 :Walker (1975) ; 17 : Keenan, Mc Manus ef Freer (1969).

$\left({ }^{2}\right)$ Génotypes. -1 : Mérinos ; 2 : Border-Leicester $\times$ Mérinos ; 3 : Romney $\times$ Swaledale ; 4 : Shropshire ; 5 : Berrichon $\times$ (Romanov $\times$ Limousin) ; 6 : Croisement Dorset ; 7 : Hampshire $\times$ Rambouillet; 8 : lle de France $\times$ (Romanov $\times$ Limousin) ; 9 : Limousin ; 10 : Charmois ; 12 : Romanov ; 13 : lle de France ; 14 : Karakul ou Mérinos ; 15 : Black Face ; 16 : Suffolk-Targhee ; 17 :Targhee ; 18 : Dorset-Horn $\times$ (Border-Leicester $\times$ Mérinos) ; 19 : Hampshire $\times$ brebis locales ; 20 : non précisé.

$\left({ }^{3}\right)$ Sexe. $-1:$ mâles entiers ; 2 : femelles ; 3 : mâles castrés. 
ANNEXE 1 (suite)

\begin{tabular}{|c|c|c|c|c|c|c|c|c|}
\hline \multirow{2}{*}{$\begin{array}{l}\text { Auteurs } \\
\text { (1) }\end{array}$} & \multirow{2}{*}{$\begin{array}{c}\text { Race } \\
\left({ }^{2}\right)\end{array}$} & \multirow{2}{*}{$\begin{array}{c}\text { Sexe } \\
\left({ }^{(3)}\right.\end{array}$} & \multirow{2}{*}{ Nombre } & \multirow{2}{*}{ Age (j) } & \multirow{2}{*}{$\begin{array}{l}\text { Poids vif } \\
\text { vide }(\mathrm{kg})\end{array}$} & \multicolumn{3}{|c|}{ p. 100 poids vif vide } \\
\hline & & & & & & Eau & Lipides & Protéines \\
\hline 5 & 6 & 3 & 4 & 237 & 35,7 & 56,80 & 24,20 & 15,20 \\
\hline 5 & 6 & 2 & 4 & 237 & 35,7 & 53,30 & 27,20 & 15,80 \\
\hline 6 & 7 & - & 5 & 90 & 27,0 & 58,17 & 23,38 & 15,44 \\
\hline 6 & 7 & - & 5 & 90 & 30,0 & 56,08 & 26,12 & 15,05 \\
\hline 6 & 7 & - & 10 & 90 & 21,3 & 62,68 & 17,18 & 16,26 \\
\hline 6 & 7 & - & 10 & 90 & 23,3 & 62,82 & 17,21 & 16,46 \\
\hline 7 & 5 & 1 & 6 & 100 & 26,7 & 62,80 & 16,40 & 17,10 \\
\hline 7 & 5 & 1 & 6 & 100 & 27,6 & 63,30 & 16,40 & 16,70 \\
\hline 7 & 5 & 1 & 6 & 99 & 27,8 & 61,80 & 17,70 & 17,10 \\
\hline 7 & 5 & 1 & 6 & 98 & 28,8 & 62,20 & 17,90 & 16,70 \\
\hline 7 & 5 & 1 & 6 & 100 & 30,3 & 62,00 & 18,50 & 16,20 \\
\hline 7 & 5 & $i$ & 3 & 56 & 15,6 & 69,00 & 9,60 & 17,70 \\
\hline 7 & 8 & $i$ & 6 & 122 & 28,8 & 63,00 & 14,90 & 18,10 \\
\hline 7 & 8 & 1 & 6 & 107 & 31,1 & 63,10 & 15,80 & 17,50 \\
\hline 7 & 8 & 2 & 6 & 141 & 27.4 & 57,10 & 21,20 & 17,60 \\
\hline 7 & 8 & 2 & 6 & 120 & 29,2 & 57,80 & 22,20 & 16,60 \\
\hline 7 & 8 & 2 & 6 & 137 & 28,6 & 56,20 & 22,70 & 17,40 \\
\hline 7 & 8 & 1 & 4 & 56 & 18,4 & 65,90 & 11,70 & 18,00 \\
\hline 7 & 8 & 2 & 4 & 56 & 16,5 & 62,70 & 15,10 & 18,00 \\
\hline 7 & 5 & $\overline{1}$ & 3 & 98 & 24,8 & 65,10 & 15,00 & 16,60 \\
\hline 7 & 5 & 1 & 5 & 105 & 28,7 & 62,70 & 17,40 & 16,60 \\
\hline 7 & 5 & 1 & 5 & 119 & 33,3 & 60,30 & 19,90 & 16,50 \\
\hline 7 & 9 & $i$ & 3 & 98 & 24,1 & 63,10 & 17,20 & 16,40 \\
\hline 7 & 9 & 1 & 5 & 112 & 27,8 & 60,50 & 19,60 & 16,50 \\
\hline 7 & 9 & 1 & 5 & 140 & 33,9 & 57,80 & 23,20 & 15,90 \\
\hline 7 & 10 & 1 & 3 & 91 & 21,0 & 64,40 & 15,90 & 16,30 \\
\hline 7 & 10 & 1 & 5 & 105 & 25,0 & 63,00 & 18,20 & 15,50 \\
\hline 7 & 10 & 1 & 4 & 112 & 28,4 & 60,70 & 20,60 & 14,20 \\
\hline 8 & 9 & - & 14 & 0 & 3,3 & 76,80 & 3,10 & 15,81 \\
\hline 8 & 8 & - & 9 & 0 & 2,8 & 75,50 & 2,70 & 17,31 \\
\hline 8 & 8 & - & 35 & 0 & 2,9 & 76,30 & 3,20 & 16,31 \\
\hline 8 & 12 & - & 5 & 0 & 2,2 & 75,60 & 4,20 & 15,87 \\
\hline 8 & 13 & - & 12 & 0 & 3,6 & 75,90 & 3,50 & 16,75 \\
\hline 9 & 14 & - & 4 & 0 & 3,9 & 77,70 & 2,55 & 15,78 \\
\hline 10 & 15 & - & 8 & 0 & 3,5 & 70,40 & 1,86 & 17,20 \\
\hline 10 & 15 & - & 9 & 0 & 3,1 & 69,59 & 1,71 & 17,08 \\
\hline 10 & 15 & - & 8 & 0 & 2,6 & 68,66 & 1,49 & 16,94 \\
\hline 10 & 15 & - & 9 & 0 & 2,4 & 68,60 & 1,35 & 16,18 \\
\hline 10 & 15 & - & 8 & 0 & 4,0 & 68,85 & 1,56 & 17,54 \\
\hline 12 & 16 & - & 26 & -77 & 0,2 & 90,40 & 0,50 & 6,25 \\
\hline 12 & 16 & - & 51 & -45 & 1,2 & 85,70 & 1,50 & 9,37 \\
\hline 12 & 16 & - & 49 & -23 & 3,4 & 83,30 & 2,10 & 11,25 \\
\hline 12 & 16 & - & 44 & -5 & 5,5 & 81,70 & 2,10 & 12,50 \\
\hline 11 & 1 & - & 6 & -57 & 0,5 & 88,30 & 0,50 & 6,20 \\
\hline 11 & 1 & - & 11 & -22 & 2,4 & 80,35 & 2,32 & 12,36 \\
\hline 11 & 1 & - & 11 & -2 & 4,4 & 78,62 & 2,60 & 13,78 \\
\hline 12 & 17 & 2 & 25 & 180 & 20,9 & 60,30 & 19,30 & 16,10 \\
\hline 12 & 17 & 2 & 18 & 420 & 30,7 & 53,20 & 28,80 & 14,50 \\
\hline 12 & 17 & 2 & 23 & 999 & 53,5 & 53,60 & 28,80 & 13,80 \\
\hline 12 & 17 & 2 & 10 & 999 & 67,2 & 44,20 & 40,40 & 12,20 \\
\hline 13 & 18 & 1 & 3 & 18 & 5,0 & 69,30 & 9,10 & 17,30 \\
\hline 13 & 18 & 1 & 3 & 18 & 6,0 & 72,30 & 3,90 & 19,50 \\
\hline 13 & 18 & 1 & 3 & 32 & 4,3 & 67,90 & 11,80 & 16,20 \\
\hline 13 & 18 & 1 & 3 & 32 & 7,7 & 71,20 & 5,50 & 19.10 \\
\hline 13 & 18 & 1 & 3 & 46 & 4,7 & 64,50 & 16,40 & 15,00 \\
\hline
\end{tabular}


ANNEXE 1 (suite)

\begin{tabular}{|c|c|c|c|c|c|c|c|c|}
\hline \multirow{2}{*}{$\begin{array}{l}\text { Auteurs } \\
\text { (1) }\end{array}$} & \multirow{2}{*}{$\begin{array}{l}\text { Race } \\
\left({ }^{2}\right)\end{array}$} & \multirow{2}{*}{$\begin{array}{c}\text { Sexe } \\
\left({ }^{3}\right)\end{array}$} & \multirow{2}{*}{ Nombre } & \multirow{2}{*}{ Age (j) } & \multirow{2}{*}{$\begin{array}{l}\text { Poids vif } \\
\text { vide }(\mathbf{k g})\end{array}$} & \multicolumn{3}{|c|}{ p. 100 poids vif vide } \\
\hline & & & & & & Eau & Lipides & Protéines \\
\hline 13 & 18 & 1 & 3 & 46 & 9,8 & 70,70 & 6,70 & 18,60 \\
\hline 13 & 18 & 1 & 16 & 4 & 4,2 & 74,10 & 2,80 & 18,56 \\
\hline 14 & 19 & 3 & 3 & - & 45,0 & 53,89 & 28,22 & 13,62 \\
\hline 14 & 19 & 3 & 3 & - & 45,0 & 51,98 & 29,98 & 13,78 \\
\hline 15 & 20 & - & 3 & 0 & 4,5 & 76,95 & 3,05 & 14,95 \\
\hline 15 & 20 & - & 2 & 31 & 9,1 & 69,98 & 11,35 & 14,02 \\
\hline 15 & 20 & - & 2 & 31 & 9,1 & 71,98 & 10,46 & 13,54 \\
\hline 15 & 20 & - & 2 & 31 & 9,1 & 70,49 & 9,33 & 16,11 \\
\hline 15 & 20 & - & 2 & 31 & 9,1 & 70,46 & 9,48 & 15,37 \\
\hline 15 & 20 & - & 2 & 31 & 9,1 & 70,73 & 9,30 & 15,67 \\
\hline 15 & 20 & - & 2 & 31 & 9,1 & 69,90 & 9,49 & 16,17 \\
\hline 15 & 20 & - & 2 & 31 & 9,1 & 67,34 & 12,91 & 15,91 \\
\hline 16 & 18 & 1 & 13 & 24 & 5,5 & 69,82 & 8,89 & 17,09 \\
\hline 16 & 18 & 1 & 13 & 24 & 5,5 & 70,01 & 8,03 & 17,76 \\
\hline 17 & 1 & 3 & 6 & 999 & 24,4 & 60,12 & 15,20 & 18,52 \\
\hline 17 & 1 & 3 & 6 & 999 & 22,6 & 61,39 & 14,02 & 18,09 \\
\hline 17 & 1 & 3 & 9 & 999 & 30,6 & 57,90 & 19,35 & 17,42 \\
\hline 17 & 1 & 3 & 3 & 999 & 28,6 & 60,72 & 15,98 & 17,35 \\
\hline
\end{tabular}


ANNEXE 2

Résultats sur la composition chimique globale des bovins en croissance

\begin{tabular}{|c|c|c|c|c|c|c|c|c|}
\hline \multirow{2}{*}{$\begin{array}{l}\text { Auteurs } \\
\text { (1) }\end{array}$} & \multirow{2}{*}{$\underset{\left({ }^{2}\right)}{\text { Race }}$} & \multirow{2}{*}{$\begin{array}{c}\text { Sexe } \\
\left({ }^{3}\right)\end{array}$} & \multirow{2}{*}{ Nombre } & \multirow{2}{*}{ Age (j) } & \multirow{2}{*}{$\begin{array}{l}\text { Poids vif } \\
\text { vide }(\mathrm{kg})\end{array}$} & \multicolumn{3}{|c|}{ p. 100 poids vif vide } \\
\hline & & & & & & Eau & Lipides & Protéines \\
\hline 1 & 1 & 2 & 6 & -108 & 6,5 & 85,17 & 1,46 & - \\
\hline 1 & 1 & 2 & 8 & -80 & 16,4 & 80,65 & 2,75 & - \\
\hline 1 & 1 & 2 & 8 & -37 & 31,8 & 76,48 & 3,43 & - \\
\hline 1 & 1 & 2 & 7 & 0 & 49,3 & 74,19 & 2,80 & 18,89 \\
\hline 1 & 1 & 2 & 17 & 93 & 66,0 & 71,75 & 4,77 & 19,00 \\
\hline 1 & 1 & 2 & 16 & 179 & 85,9 & 69,07 & 7,20 & 19,41 \\
\hline 1 & 1 & 2 & 10 & 273 & 141,1 & 66,22 & 10,05 & 19,22 \\
\hline 1 & 1 & 2 & 9 & 371 & 160,9 & 63,75 & 12,66 & 19,17 \\
\hline 1 & 1 & 2 & 9 & 1052 & 308,9 & 58,44 & 17,85 & 18,40 \\
\hline 2 & 3 & - & 2 & -193 & 0,3 & 90,46 & 0,39 & 6,59 \\
\hline 2 & 3 & - & 4 & -151 & 1,2 & 88,99 & 0,63 & 7,45 \\
\hline 2 & 3 & - & 5 & -124 & 3,6 & 86,06 & 1,18 & 9,15 \\
\hline 2 & 3 & - & 4 & -56 & 11,7 & 81,14 & 2,35 & 12,48 \\
\hline 2 & 3 & - & 3 & -20 & 28,2 & 76,58 & 3,43 & 15,16 \\
\hline 3 & 1 & 3 & 5 & - & 45,0 & 71,84 & 4,00 & 19,89 \\
\hline 3 & 1 & 3 & 4 & - & 91,0 & 70,43 & 6,01 & 19,14 \\
\hline 3 & 1 & 3 & 4 & - & 136,0 & 65,72 & 11,19 & 18,77 \\
\hline 3 & 1 & 3 & 5 & - & 182,0 & 65,79 & 10,56 & 19,31 \\
\hline 3 & 1 & 3 & 5 & - & 227,0 & 62,90 & 13,73 & 19,15 \\
\hline 3 & 1 & 3 & 3 & - & 273,0 & 61,20 & 15,04 & 19,40 \\
\hline 3 & 1 & 3 & 4 & - & 318,0 & 60,35 & 16,58 & 18,60 \\
\hline 3 & 1 & 3 & 3 & - & 364,0 & 58,44 & 18,52 & 18,80 \\
\hline 3 & 1 & 3 & 3 & - & 409,0 & 54,10 & 24,08 & 17,66 \\
\hline 3 & 1 & 3 & 4 & - & 455,0 & 52,03 & 26,91 & 17,11 \\
\hline 3 & 1 & 3 & 10 & - & 590,0 & 46,98 & 33,40 & 16,01 \\
\hline 4 & 1 & 3 & 6 & 141 & 87,0 & 66,69 & 7,90 & 20,11 \\
\hline 4 & 1 & 3 & 5 & 269 & 152,0 & 60,95 & 15,30 & 18,52 \\
\hline 4 & 1 & 3 & 4 & 455 & 374,0 & 52,73 & 25,57 & 17,33 \\
\hline 4 & 1 & 3 & 4 & 1252 & 761,0 & 40,24 & 42,54 & 13,14 \\
\hline 5 & 1 & 3 & 8 & - & 196,0 & 62,00 & 15,31 & 19,42 \\
\hline 5 & 1 & 3 & 16 & - & 315,0 & 60,70 & 18,90 & 17,78 \\
\hline 5 & 1 & 3 & 16 & - & 429,0 & 54,43 & 27,66 & 15,99 \\
\hline 5 & 1 & 3 & 16 & - & 509,0 & 49,86 & 33,25 & 15,00 \\
\hline 6 & 3 & 2 & 16 & 520 & 254,0 & 64,50 & 9,77 & 19,33 \\
\hline 7 & 4 & 1 & 4 & - & 153,0 & 66,69 & 8,23 & 17,90 \\
\hline 7 & 4 & 1 & 8 & - & 258,0 & 63,37 & 12,95 & 17,94 \\
\hline 8 & 4 & $i$ & 43 & 546 & 485,0 & 55,60 & 21,80 & 17,50 \\
\hline 9 & 4 & 1 & 9 & 10 & 41,0 & - & 4,80 & 18,90 \\
\hline 9 & 4 & $i$ & 10 & 90 & 71,0 & - & 5,00 & 19,20 \\
\hline 9 & 4 & 1 & 7 & 120 & 86,0 & - & 6,20 & 19,30 \\
\hline 9 & 4 & 1 & 4 & - & 123,0 & 一 & 7,00 & 19,40 \\
\hline 9 & 4 & 1 & 4 & - & 157,0 & - & 9,40 & 19,20 \\
\hline 9 & 4 & 1 & 4 & - & 205,0 & - & 10,90 & 19,50 \\
\hline 9 & 4 & 1 & 6 & - & 362,0 & - & 14,40 & 19,50 \\
\hline
\end{tabular}

(1) Auteurs. - 1 : Ellenberger, Newlander ef Jones (1950); 2 : Jakobsen (1957) ; 3 : Haecker (1920); 4 : Moulton, Trowbridge ef Haigh (1922) ; 5 : Jesse ef al. (1976) ; 6 : Foot et Tulloh (1977) ; 7 : Holzchuh (1966) ; 8 : Pfau (1969) ; 9 : Osinska et Ziolecka (1972) ; 10 : Schultz, Oslage et Daenicke (1974) ; 11 : Daenicke et Rohr $(1978) ; 12$ : Jentsch et Schieman (1976);13 : Robelin et Geay (1978 et résultats non publiés).

$\left({ }^{2}\right)$ Génotypes. -1 : Hereford ; 2 : Angus ; 3 : Rouge Danois ; 4 : Frison ; 5 : Charolais $\times$ Frison ; 6 : Simmental ; 7 : Salers ; 8 : Charolais $\times$ Salers ; 9 : Limousin ; 10 : Charolais.

$\left.{ }^{3}\right)$ Sexe. -1 : mâles entiers ; 2 : femelles ; 3 : mâles castrés. 
ANNEXE 2 (suite)

\begin{tabular}{|c|c|c|c|c|c|c|c|c|}
\hline \multirow{2}{*}{$\begin{array}{c}\text { Auteurs } \\
\left({ }^{1}\right)\end{array}$} & \multirow{2}{*}{$\begin{array}{l}\text { Race } \\
\left({ }^{2}\right)\end{array}$} & \multirow{2}{*}{$\begin{array}{c}\text { Sexe } \\
\left({ }^{3}\right)\end{array}$} & \multirow{2}{*}{ Nombre } & \multirow{2}{*}{ Age (j) } & \multirow{2}{*}{$\begin{array}{l}\text { Poids vif } \\
\text { vide }(\mathrm{kg})\end{array}$} & \multicolumn{3}{|c|}{ p. 100 poids vif vide } \\
\hline & & & & & & Eau & Lipides & Protéines \\
\hline 10 & 4 & 1 & 6 & 147 & 123,0 & 69,94 & 6,74 & 18,84 \\
\hline 10 & 4 & 1 & 6 & 259 & 217,0 & 68,81 & 7,71 & 19,13 \\
\hline 10 & 4 & 1 & 8 & 364 & 309,0 & 64,42 & 11.84 & 19,28 \\
\hline 10 & 4 & 1 & 12 & 477 & 416,0 & 60,79 & 16,24 & 18,48 \\
\hline 10 & 4 & 1 & 12 & 574 & 509,0 & 55,69 & 22,78 & 17,38 \\
\hline 11 & 4 & 1 & 4 & - & 132,0 & 69,20 & 7,44 & 18,99 \\
\hline 11 & 4 & 1 & 14 & - & 500,0 & 56,28 & 22,68 & 17,55 \\
\hline 11 & 4 & 1 & 14 & - & 544,0 & 54,41 & 24,29 & 17,00 \\
\hline 12 & 4 & 1 & 20 & - & 40,00 & 74,70 & 3,74 & 16,67 \\
\hline 12 & 4 & 1 & 4 & - & 116,0 & 72,60 & 4,58 & 16,80 \\
\hline 12 & 4 & $i$ & 4 & 一 & 301,0 & 66,20 & 12,40 & 16,80 \\
\hline 12 & 4 & 1 & 7 & - & 498,0 & 58,60 & 21,69 & 15,81 \\
\hline 13 & 4 & 1 & 5 & 120 & 108,0 & 70,14 & 5,74 & 19,24 \\
\hline 13 & 4 & 1 & 5 & 210 & 185,0 & 67,99 & 8,93 & 18,56 \\
\hline 13 & 4 & 1 & 5 & 280 & 279,0 & 65,06 & 12,68 & 18,26 \\
\hline 13 & 4 & 1 & 2 & 350 & 352,0 & 61,15 & 16,50 & 18,19 \\
\hline 13 & 4 & 1 & 2 & 450 & 454,0 & 56,67 & 21,85 & 17,26 \\
\hline 13 & 4 & 1 & 2 & 570 & 528,0 & 54,72 & 24,43 & 16,74 \\
\hline 13 & 5 & 1 & 2 & 130 & 117,0 & 71,02 & 5,24 & 19,00 \\
\hline 13 & 5 & 1 & $\overline{2}$ & 220 & 231,0 & 66,59 & 10,69 & 18,67 \\
\hline 13 & 5 & 1 & 2 & 290 & 305,0 & 63,78 & 13,70 & 18,49 \\
\hline 13 & 5 & 1 & 2 & 370 & 411,0 & 61,17 & 15,75 & 18,71 \\
\hline 13 & 5 & 1 & 2 & 480 & 493,0 & 58,01 & 20,61 & 17,38 \\
\hline 13 & 5 & 1 & 2 & 560 & 600,0 & 60,30 & 17,76 & 18,12 \\
\hline 11 & 6 & 1 & 4 & - & 132,0 & 68,06 & 8,72 & 19,13 \\
\hline 11 & 6 & 1 & 14 & - & 500,0 & 60,32 & 16,42 & 19,22 \\
\hline 11 & 6 & 1 & 14 & - & 545,0 & 58,29 & 19,04 & 18,80 \\
\hline 13 & 7 & 1 & 5 & 270 & 234,0 & 67,02 & 9,19 & 18,89 \\
\hline 13 & 7 & 1 & 15 & 480 & 470,0 & 62,97 & 13,18 & 19,32 \\
\hline 13 & 8 & 1 & 4 & 270 & 264,0 & 68,06 & 7,86 & 19,26 \\
\hline 13 & 9 & 1 & 5 & 290 & 260,0 & 66,50 & 9,08 & 19,69 \\
\hline 13 & 9 & 1 & 5 & 390 & 390,0 & 66,52 & 9,70 & 19,83 \\
\hline 13 & 9 & 1 & 10 & 480 & 488,0 & 64,26 & 11,46 & 20,03 \\
\hline 13 & 9 & 1 & 10 & 570 & 577,0 & 63,13 & 12,53 & 20,21 \\
\hline 13 & 10 & $i$ & 5 & 140 & 142,0 & 71,49 & 5,63 & 18,67 \\
\hline 13 & 10 & 1 & 5 & 260 & 257,0 & 67,42 & 8,81 & 19,19 \\
\hline 13 & 10 & 1 & 5 & 340 & 343,0 & 65,79 & 11,84 & 18,57 \\
\hline 13 & 10 & 1 & 2 & 440 & 453,0 & 65,66 & 11,63 & 19,07 \\
\hline 13 & 10 & 1 & 2 & 510 & 514,0 & 63,30 & 13,16 & 19,32 \\
\hline 13 & 10 & 1 & 2 & 640 & 648,0 & 64,04 & 13,23 & 18,91 \\
\hline
\end{tabular}




\section{Références}

ANDREWS R. P., KAY M., ORSKOV E. R., 1996. The effects of dietary energy concentration on the voluntary intake and growth of intensively fed lambs. Anim. Prod, 11, 173-186.

ANDREWS R. P., ORSKOV E. R., 1970. The nutrition of the early weaned lamb. I. The influence effect of dietary protein concentration, feeding level and sex on body composition at two liveweights. J. afric. Sci., 75, 19-26.

ARNAL M., 1977. Muscle protein turnover in lambs throughout development, 35-37, Proc. 2nd int. Symp. on Protein metabolism and nutrition, EAAP, n० 22, PUDOC Wageningen.

ARNOLD G. W., GHARAYBEH H. R., DUDZINSKI M. L., MCMANUS W. R., AXELSEN A., 1969. Body composition of young sheep. II. Effect of stocking rate on body composition of Dorset horn cross lambs. J. agric. Sci., 72, 77-84.

BURTON J. H., REID J. T., 1969. Interrelationships among energy input, body size, age and body composition in sheep. J. Nutr., 97, 517-524.

CHIOU W. S., JORDAN R. M., 1973. Ewe milk replacer diets for young lambs. III. Effects of age of lambs and diefary protein and fat levels on the body composition of young lambs. J. anim. sci., 36, 607-612.

DAENICKE R., ROHR K., 1978. Influence of nutrition on body composition and carcass quality of fattening bulls of two different breeds (Friesian and Simmental), 423-424, In De BOER H., MARTIN J., Patterns of growth and developemnt in cattle. Proc. E.E.C. Seminar, Ghent, 1977. Martinus Nijhof, The Hague.

DELPECH P., 1966. Le poids frais délipidé chez Gallus Gallus. C. R. Acad. Sci., Paris, 263, 1735-1738.

DREW K. R., REID J. T., 1975. Compensatory growth in immature sheep. I. The effects of weight loss and realimentation on the whole body composition. J. agric. Sci., 85, 193-204.

ELLENBERGER H. B., NEWLANDER J. A., JONES C. H., 1950. Composition of the bodies of dairy cattle. Vermont agr. exper. Stat., Bull. $\mathrm{n}: 558,1-66$.

FOOT J. Z., TULLOH N. M., 1977. Effects of two paths of liveweight change on the efficiency of feed use and on body composition of Angus steers. J. agric. Sci., 88, 135-142.

GARDNER R.W., HOGUE D. E., BENSADOUN A., 1964. Body composition and efficiency of growth of suckling lambs as affected by level of feed intake. J. onim. Sci., 23, 943-952.

GEAY Y., ROBELIN J., BERANGER C., 1976. Influence du niveau aimentaire sur le gain de poids vif et la composition de la carcasse de taurillons de différentes races. Ann. Zootech., $25,287$. 298.

GEAY Y., ROBELIN J., BERANGER C., MICOL D., 1978. Besoins alimentaires des bovins en croissance et à l'engrais. In Alimentation des Ruminants, 243-297. Ed. I.N.R.A. Publ. Versailles.

GHARAYBEH H. R., MCMANUS W. R., ARNOLD G. W., DUDZINSKI M. L., 1969. Body composition of young sheep. I. Body composition in Merino and Border-Leicester $\times$ Merino hoggets in relation to and at common empty body wieght. J. agric. Sci., 72, 65-75.

HAECKER T. L., 1920. Quoted in BERG R. T., BUTTERFIELD R. M., 1976, 50, New concepts of cattle growth. Sydney Univ. Press.

HOLZSCHUH W., 1966. Wachstum versuch verbunden mit körperanalysen bei Jungmastbullen zur Ermittlung des N-ansatzes aus NPN-verbindungen. Arch. Tierzucht., 9, 159-176.

JAGUSCH K. T., NORTON B. W., WALKER D. M., 1970. Body composition studies with the milkfed lamb. II. The effect of the age of the lamb and the protein content of the diet on the chemical composition of the body and its organs. J. agric. Sci., 75, 279-285.

JAKOBSEN P. E., 1957. Proteinbehov og proteinsynthese ved fosterdannelse hos drovtyggere. Forsogslab, Kobenhovn Berefn., 299, 1-90.

JARRIGE R., GUEGUEN L., ROBELIN J., THERIEZ M., 1978. Croissance. In Alimentation des Ruminants, 217-227. Ed. I.N.R.A. Publ., Versailles.

JARRIGE R., JOURNET M., VÉRITE R., 1978. Azote. In Alimentation des Ruminants, 89-128. Ed. I.N.R.A. Publ., Versailles.

JENTSCH W., SCHIEMAN R., 1976. Die Verwertung der Futterenergie durch wachsenden Bullen. Arch. Tierernährg., 27, 545-562. 
JESSE G. W., THOMPSON G. B., CLARK J. L., HEDRICK H. B., WEIMER K. G., 1976, Effects of ration energy and slaughter wieght on composition of empty body and carcass gain of beef cattle. J. anim. Sci., 43, 418-425,

KEENAN D. M., MCMANUS W. R., FREER M., 1969. Changes in the body and efficiency of mature sheep during loss and regain of liveweight. J. agric. Sci., 72, 139-148.

KELLAWAY R. C., 1973. The effects of plane of nutrition, genotype and sex on growth, body composition and wool production in grazing sheep J. agric. Sci., 80, 17-27.

LANGLANDS J. P., SUTHERLAND H. A. M., 1968. An estimate of the nutrients utilized for pregnancy by Merino sheep. Br. J. Nutr., 22, 217-227.

MCDONALD I., GREENHALGH J. F. D., GRUBB D. A., 1978. The protein, fat and energy contents of the gains made by growing sheep, estimated from comparative slaughter data. Agr. Res. Counc. Work. Party on Nutrient requierements of ruminants.

MCMANUS W. R., ARNOLD G. W., DUDZINSKI M. L., GHARAYBEH H. R., 1974. Body composition of young sheep. III. Effect of intake and pasture species on body composition and ruminal development of Merino lambs. Aust. J. exp. Agric. onim. Husb., 14, 604-612.

MILLWARD D. J., GARLICK P. J., STEWART R. J. C., NNANYELLUGO D. O., WATERLOW J. C., 1975. Skeletal muscle growth and protein turnover. Biochem. J., 150, 235-243.

MORGAN J. A., OWEN J. B., 1972. The nutrition of the artificially reared lamb. 2. The effect of feed restriction at three stages of growth on growth and carcass composition. Anim. Prod., 15, 293301.

MOULTON C. R., 1923. Age and chemical development in mammals. J. biol. Chem., 57, 79-97.

MOULTON C. R., TROWBRIDGE P. F., HAIGH L. D., 1922. Studies in animal nutrition. III. Changes in chemical composition on different planes of nutrition. Missouri Agric. exper. Stat., Bull. $n^{\circ} 55$, $1-87$.

MURRAY D. M., SLEZACEK O., 1976. Growth rate and its effects on empty body weight, carcass weight and dissected carcass composition of sheep. J. agric. Sci., 87, 171-179.

NORTON B. W., JAGUSCH K. T., WALKER D. M., 1970. Body composition studies with the milk-fed lamb. III. The effect of the protein and energy intake on the composition of the liveweight gain. J. agric. Sci., 75, 287-292.

O'DONOVAN W. M., 1974. Developmental changes in the bodies of dorper sheep. IV. Effects of rate of live body-mass gain and energy concentration of diet on body composition of weaned dorper lambs. Rhod. J. agric. Sci., 12, 113-125.

OSINSKA Z., ZIOLECKA A., 1972. A note on the protein content of the empty body of young Polish Black and White Lowland Bulls. Anim. Prod., 14, 119-122.

PALSSON H., VERGES J. B., 1952. Effect of plane of nutrition on growth and development of carcass quality in lambs. II. Effects on lambs of $30 \mathrm{lb}$ carcass weight. J. agric. Sci., 42, 93-149.

PFAU A., 1969. Statistish abgeleitete Relationen zur Bestimmung der grosschemischen Körperzusammensetzung beim Rind. Z. Tierzucht Zücht., 85, 363-369.

RATTRAY P. V., GARRETT W. N., EAST N. E., HINMAN N., 1974a. Growth, development and composition of the ovine conceptus and mammary gland during pregnancy. J. anim. Sci., 38, 613-626.

RATTRAY P. B., GARRETT W. N., HINMAN N., EAST N. E., 1974b. Effects of level of nutrition, pregnancy and age on the composition of the wool-free ingesta-free body and carcass of sheep. J. anim. Sci., 39, 687-693.

ROBELIN J., 1979. Influence de la vitesse de croissance sur la composition du gain de poids des bovins : variations selon la race et le sexe. Ann. Zootech., 28, 209-218.

ROBELIN J., DAENICKE R., 1980. Variations of net requirements for cattle growth with liveweight, liveweight gain, breed and sex. In Energy and protein feeding standards for beef cattle. Proc. E.E.C. Seminar., Ann. Zoofech., 29, 99-118.

ROBELIN J., GEAY Y., 1978. Estimation de la composition chimique du corps entier des bovins à partir du poids des dépôts adipeux totaux. Ann. Zootech., 25, 159-167.

ROBELIN J., GEAY Y., BERANGER C., 1974. Croissance relative des différents tissus, organes et régions corporelles des taurillons Frisons, durant la phase d'engraissement de 9 à 15 mois. Ann. Zootech., 23, 313-323.

ROBELIN J., GEAY Y., BERANGER C., 1977. Evolution de la composition corporelle des jeunes bovins mâles entiers de race Limousine entre 9 et 19 mois. I. Composition anatomique. Ann. Zootech., 26, 533-546. 
ROBELIN J., GEAY Y., BERANGER C., 1979. Evolution de la composition corporelle des jeunes bovins mâles entiers de race Limousine entre 9 et 19 mois. II. Composition chimique et valeur calorifique. Ann. Zoofech., 28, 191-208.

ROBELIN J., GEAY Y., BONAITI B., 1978. Genetic variations in growth and body composition of male cattle, 443-460. In De BOOER H., MARTIN J., Patterns of growth and development in cattle. Proc. E. E. C. Seminar. Ghent, 1977. Martinus Nijhof, The Hague.

ROBELIN J., THÉRIEZ M., ARNAL M., FERRARA M., 1977. Evolution de la composition chimique de jeunes agneaux mâles jusqu'à l'âge de 16 semaines. Ann. Zootech., 26, 69-81.

SCHULTZ E., OSLAGE H. J., DAENICKE R., 1974. Untersuchugen über die Zugammensetzung der Körpersubstanz sowie den Stoff - und Energieansatz bei wachsenden Mastbullen. Z. Tierphysiol. Tierernährg Futtermittelkde, 4, 1-70.

SEARLE T. W., MCGRAHAM N., 1972. Comparison of body composition of energy utilization befween Merino and fixed halfbred (Border-Leicester $\times$ Merino) wethers. J. agric. Sci., 23, 339-346.

SEARLE T. W., McGRAHAM N., O'CALLAGAN M., 1972. Growth in sheep. I. The chemical composition of body. J. agric. Sci., 79, 371-382.

SYKES A. R., FIELD A. C., 1972. Effect of dietary deficiency of energy protein and calcium on pregnant ewe. II. Body composition and mineral content of the lamb. J. agric. Sci., 78, 119-125.

TISSIER M., THÉRIEZ M., 1978. Ovins. In Alimentation des Ruminants, 403-448. Ed. I.N.R.A. Publ., Versailles.

VIGNERON P., BARON R., DAUZIER L., 1971. Evolution postnatale de la quantité d'eau et de lipides du corps et du grand psoas chez le lapin. Ann. Biol. anim. Bioch. Biophys., 11, 669-679.

WALKER D. M., 1975. Methionine supplementation of milk protein for preruminant lambs. Il. Effect on wool growth, liveweight gain and body composition. Aust. J. agric. Res., 26, 681-688.

WENINGER J. H., FUNK K., KONIG K. H., 1955. Untersuchungen über den Calcium, Phosphor und Nährstoffgehalt von Schafen und Ziegen. Arch. Tierernähr, 5, 216-224.

WIDDOWSON E. M., 1968. Biological implications of body composition, 71-79. In Body composition in animals and man, Nat. Acad. Sci., Publ. 1598, Washington. 